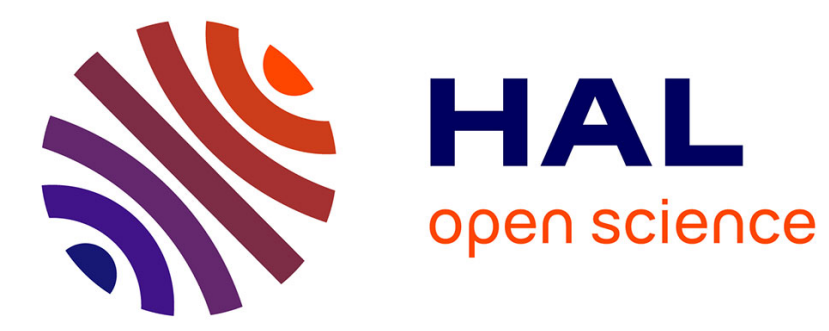

\title{
XAFS Measurements of Rb-O Bonds in Ambient and Supercritical Water
}

\author{
M. Newville, J. Fulton, D. Pfund, S. Wallen, E. Stern, Y. Ma
}

\section{To cite this version:}

M. Newville, J. Fulton, D. Pfund, S. Wallen, E. Stern, et al.. XAFS Measurements of Rb-O Bonds in Ambient and Supercritical Water. Journal de Physique IV Proceedings, 1997, 7 (C2), pp.C2-1007C2-1008. 10.1051/jp4:19972118 . jpa-00255176

\section{HAL Id: jpa-00255176 https://hal.science/jpa-00255176}

Submitted on 1 Jan 1997

HAL is a multi-disciplinary open access archive for the deposit and dissemination of scientific research documents, whether they are published or not. The documents may come from teaching and research institutions in France or abroad, or from public or private research centers.
L'archive ouverte pluridisciplinaire HAL, est destinée au dépôt et à la diffusion de documents scientifiques de niveau recherche, publiés ou non, émanant des établissements d'enseignement et de recherche français ou étrangers, des laboratoires publics ou privés. 


\title{
XAFS Measurements of Rb-O Bonds in Ambient and Supercritical Water
}

\author{
M. Newville, J.L. Fulton*, D.M. Pfund*, S.L. Wallen*, E.A. Stern** and Y. Ma** \\ Lawrence Livermore National Laboratory, L-219, Livermore, CA 94550, U.S.A. \\ * Pacific Northwest National Laboratory, Richland, WA 99352, U.S.A. \\ ** Department of Physics, Box 351560, University of Washington, Seattle, WA 98195, U.S.A.
}

\begin{abstract}
XAFS measurements and analyses of $\mathrm{Rb}^{+}$ions in 0.5 molal $\mathrm{RbBr}$ at ambient and several supercritical $\left(P>P_{c}=220 \mathrm{bar}, T>T_{c}=374^{\circ} \mathrm{C}\right.$ ) conditions are presented. The first coordination shell of $\mathrm{Rb}^{+}$ion is seen to be dominated by oxygen from nearby water molecules. Upon going from ambient to supercritical conditions, the Rb-O coordination number decreases significantly, and the $\mathrm{Rb}-\mathrm{O}$ distance decreases by $\sim 0.10 \AA$ relative to the ambient $\mathrm{Rb}-\mathrm{O}$ distance $(\sim 2.93 \AA$ ). Although ion pairing has been predicted for supercritical conditions (due in part to a substantial decrease of the dielectric constant at the critical point), and has been observed with XAFS in other aqueous solutions, we see no direct evidence of pairing of $\mathrm{Br}^{-}$with $\mathrm{Rb}^{+}$in our measurements.
\end{abstract}

\section{INTRODUCTION}

The solubility of ions in water changes considerably around its critical point, where the density is roughly half that of ambient water, and the dielectric constant ranges from 5-20, much less than that of ambient water $(\epsilon=80)$. The high variability of these properties near and above the critical point allows the solubility of various ions to be "tuned" by changing the external conditions. Because of this, supercritical water (SCW) is an interesting solvent for many applications. It is expected that ion-pairs will form as the solubility decreases near the critical point, though very few direct structural measurements have been made on ions in SCW[1].

\section{XAFS MEASUREMENTS AND ANALYSIS}

XAFS measurements on the $\mathrm{Rb} K$-edge $(15.200 \mathrm{KeV})$ of 0.5 molal $\mathrm{RbBr}$ in water were made in transmission at beamline X-19A of NSLS using a $(220)$ monochromator crystal, detuned to pass $60 \%$ of the maximum intensity. Two focusing mirrors were used to give a beamsize of $1-2 \mathrm{~mm}$. The sample was contained in a high-pressure, hightemperature cell with a $5.8 \mathrm{~mm}$ path length and two $3 \mathrm{~mm} \times 0.5 \mathrm{~mm}$ polycrystalline diamond windows which the $\mathrm{x}$-rays passed through. The temperature and pressure of the sample were maintained to $\pm 1^{\circ} \mathrm{C}$ and \pm 1 bar, respectively. Further experimental details are given elsewhere[1, 2].

Several (5-10) experimental scans were taken at each temperature and pressure and then averaged. Figure 1 shows the averages of the measured $\mu(E)$ for the different conditions, after removing a pre-edge line. From the step height, the amount of $\mathrm{Rb}$ in the beampath is seen to vary by a factor of two, reflecting the change in solution density as a function of temperature and pressure.

The measured absorption $\mu(E)$ was reduced to $\chi(k)$ using AUTOBK[3], using the step height for the normalization. Figure 2 shows the resulting $k^{2} \chi(k)$. From these spectra several qualitative conclusions can be made: 1) the $\mathrm{Rb}$ ion

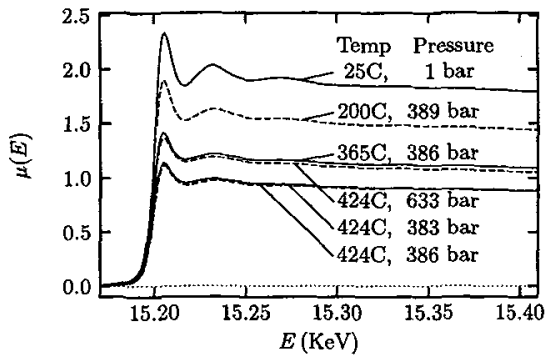

Figure 1: X-ray absorption coefficient $\mu(E)$ at the $\mathrm{Rb}$ edge for $0.5 \mathrm{~m} \mathrm{Rb}$ in water at several temperatures and pressures. From the step height, the density of the solution is seen to vary by a factor of two.

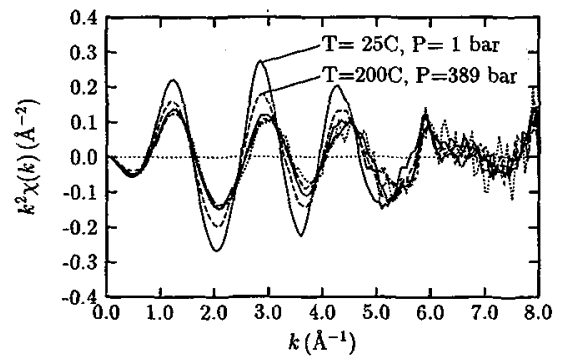

Figure 2: $k^{2} \chi(k)$ for $0.5 \mathrm{~m} \mathrm{Rb}$ in water. Spectra in ambient water and water at $T=200^{\circ} \mathrm{C}$ and $P=389 \mathrm{bar}$ are marked. Four other spectra of $\mathrm{Rb}$ in water near its critical point are also shown and are virtually identical. 
Table I: Results of XAFS analysis for Rb-O bonds in a $0.5 \mathrm{~m}$ $\mathrm{Rb}$ aqueous solution as a function of temperature $T$ and pressure $P$. Here $N$ is number of axygen neighbors, $R$ is the $R b-O$ distance, $\sigma^{2}$ is the disorder in the Rb-O distance, and $E_{0}$ is the shift of energy reference for the scattered photo-electron. Bestfit values from FEFFIT are given with uncertainties in parentheses.

\begin{tabular}{|cccccc|}
\hline$T\left({ }^{\circ} \mathrm{C}\right)$ & $P($ bar $)$ & $N$ & $R(\AA)$ & $\sigma^{2}\left(\AA^{2}\right)$ & $E_{0}(\mathrm{eV})$ \\
\hline 25 & 1 & $5.6(0.7)$ & $2.93(03)$ & $0.0341(37)$ & $-0.1(1.0)$ \\
200 & 389 & $4.4(0.8)$ & $2.87(03)$ & $0.0376(55)$ & $-2.5(1.0)$ \\
365 & 389 & $3.5(0.8)$ & $2.83(03)$ & $0.0339(63)$ & $-3.0(1.0)$ \\
424 & 383 & $3.4(1.0)$ & $2.82(04)$ & $0.0391(77)$ & $-2.9(1.0)$ \\
424 & 386 & $3.6(0.9)$ & $2.79(03)$ & $0.0411(82)$ & $-3.6(1.0)$ \\
424 & 633 & $3.9(0.7)$ & $2.81(03)$ & $0.0464(60)$ & $-3.7(1.0)$ \\
\hline
\end{tabular}

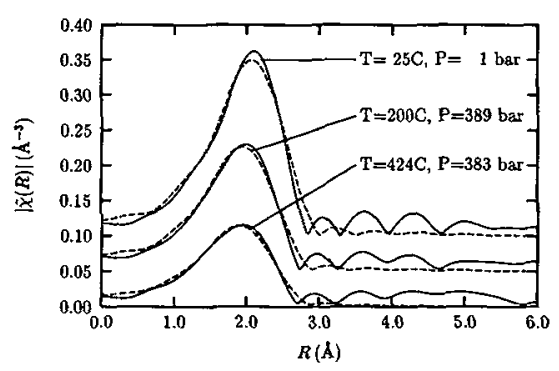

Figure 3: $|\chi(R)|$ for XAFS data (solid) of $0.5 \mathrm{~m} \mathrm{Rb}$ in water at ambient and two supercritical conditions, and best-fit (dashed) to these data, using FEFF and the parameters listed in Table I.

is largely coordinated by one atomic species at one distance (one frequency dominates), 2) the coordination number is lower for the SCW conditions than for ambient water $(\chi(k)$ is smaller even at low- $k$ for the SCW spectra), and 3 ) the near-neighbor distance is shorter in SCW than in ambient water (the SCW oscillations have longer periods).

Quantitative analyses of the $6 \chi(k)$ scans using FEFFIT[4] confirm the qualitative observations. Calculations from FEFF[5] for Rb-O bonds at distances ranging from 2.75 to $3.10 \AA$, were used as the basis functions in the analysis. Fits to each of the six sets of data were done in $R$-space, between $R=[1.40,2.90] \AA$, after Fourier transforming $k^{2} \chi(k)$ between $k=[1.0,6.5] \AA^{-1}$, using a Hanning window function with $d k=1.0 \AA^{-1}$. The usual XAFS parameters of $N$, $R, E_{0}$, and $\sigma^{2}$ were used to modify the FEFF calculations until a best-fit to each spectrum was found. The number of fitted parameters $(4)$ was below the number of independent points $(\sim 6)$ in the data[6]. The numerical fit results are given in Table I. Figure 3 shows the $|\chi(R)|$ for the data at ambient and two supercritical conditions, and the best-fits to these data. All fits were of a similarly good quality. Further details of the analysis are given elsewhere[7].

\section{RESULTS AND CONCLUSIONS}

As the $\mathrm{RbBr}$ solution changes from ambient to supercritical conditions, we find a contraction of the $\mathrm{Rb}-\mathrm{O}$ bond length $(\sim 0.10 \AA$ ), a reduction of the coordination number (from $\sim 6$ to $\sim 4$ ), and a small increase in mean-square-disorder (see Table I). These results are qualitatively similar to those of Pfund et al.[1] for $\mathrm{Sr}-\mathrm{O}$ bonds in SCW. We also see a change of $\sim 3 \mathrm{eV}$ in $E_{0}$ when going from ambient to supercritical conditions. This change may be related to the changing of electronic configuration, ionicity, and strength of the Rb-O (or Rb-water) bond as the coordination number and bond length are both reduced in SCW. No significant change in the near-edge structure was observed. Since $E_{0}$ and $R$ are highly (and positively) correlated, requiring $E_{0}$ to be constant for all conditions would give a bond length contraction of $\sim 0.07 \AA$. Such fits are significantly worse than fits in which $E_{0}$ can vary freely.

To further test the reliability of the large bond length contraction, fits that included a third cumulant were tried. These were found to not significantly improve the quality of the fit. This finding and the fact the $\sigma^{2}$ does not dramatically increase, lead us to conclude that the bonds are not very anharmonic. The large contraction of the bond length then appears to be reliable, and not an artifact of neglecting the anharmonicity of the bond.

The contraction of the bond length and the reduction of the $O$ coordination number in SCW may be due, in part, to the presence of $\mathrm{Br}$ within a few atomic distances of the $\mathrm{Rb}$ atoms. To look for such ion-pairing, we have included $\mathrm{Rb}-\mathrm{Br}$ contributions at a variety of distances in the fits. We find no appreciable amount of $\mathrm{Rb}-\mathrm{Br}$ or $\mathrm{Rb}-\mathrm{O}$ bonds in a second coordination shell, so that no direct evidence of ion-pairing is seen.

In conclusion, we have measured the local $\mathrm{Rb}$ environment of $0.5 \mathrm{~m} \mathrm{RbBr}$ in water at ambient and supercritical conditions with XAFS. We see significant decrease in the Rb-O bond length and coordination number between ambient and supercritical water. Although ion pair formation is expected as the ion solubility decreases near the critical point, we see no direct evidence of $\mathrm{Rb}-\mathrm{Br}$ bonding.

\section{References}

[1] Pfund D. M., Darab J. C., Fulton J. L., Ma Y. J. Phys. Chem., 98, (1994), 13102-13107.

[2] Fulton J. L., Pfund D. M., Ma Y. Rev. Sci. Instrum., in press, (1996).

[3] Newville M., P. Liviņs, Yacoby Y., Rehr J. J., Stern E. A. Phys. Rev. B, 47, (1993), 14126-14131.

[4] Newville M., Stern E. A. Phys. Rev. B, submitted, (1996).

[5] Zabinsky S. I., Rehr J. J., Ankudinov A., Albers R. C., Eller M. J. Phys. Rev. B, 52, (1995), $2995-3009$.

[6] Lytle F. W., Sayers D. E., Stern E. A. Physica B, 158, (1989), 701-722.

[7] Fulton J. L., Pfund D. M., Wallen S. L., Newville M., Stern E. A., Ma Y. J. Chem. Phys., 105, (1996), $2161-2164$. 